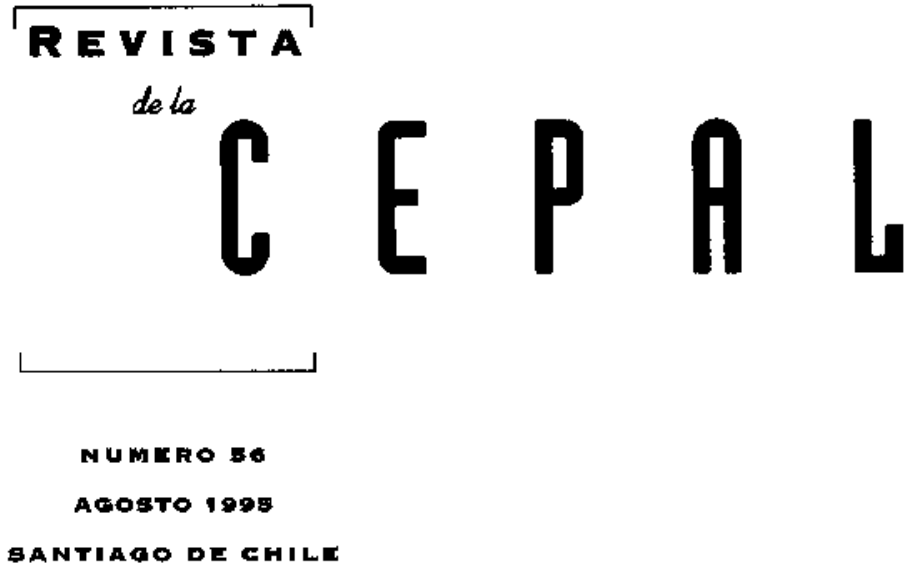

ANIBAL PINTO

Director

EUGENIO LAHERA

Secretario Técnico

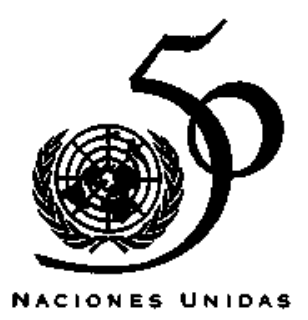


Democracla y desarrollo

Fernando H. Cardoso

¿Es posible crecer con equidad?

Joseph Ramos

Estabilidad y estructura: Interacclones en el crecimiento económlco

Jose Maria Fanelli y Roberto Frenkel

Reforma a los sistemas de pensiones en América Latina

Andras Uthoff

Tendenclas económicas en China: significado para el comerclo con América Latina y el Caribe

Mikio Kuwayama

El Intercamblo económico entre América Latina y las

economias dinámicas de Asla

Ronald Sprout

La relación económica entre la Amórica Latina y la Unlón Europea

Roberto Smith Perera

Nuevas implicaclones de las reglas do orlgen

Eduardo Gitli

Globalización y reestructuración energética en Amórlca Latina

Fernando Sánchez Albavera

El caloidoscoplo de la competitlvidad

Geraldo Muller

La privatización de los servicios públicos del agua

Miguel Solanes

¿Cuénto se puede gastar en educaclón?

Guillermo Labarca

Mujeres y migranteo: deslgualdades en el

mercado laboral de Santlago de Chile

Ivonne Szasz

Orlentaciones para los colaboradores de la Rovista de la CEPAL 


\section{El intercambio económico entre América Latina y las economías dinámicas de Asia}

\section{Ronald V. A. Sprout \\ Economista, Oficina para Europa y los Nuevos Estados Independientes de la ex Union Soviética, Agencia de los Estados Unidos para el Desarrollo Internacional. Docente del Trinity College, $y$ de la American University en Washington, D.C.}

Este artículo examina las relaciones económicas Sur-Sur en el contexto del regionalismo. Abarca tres economías de America Latina, y ocho economías dinámicas del Asia en desarro. llo. Aunque el nivel de comercio e inversión entre estos dos grupos de economfas en desarrollo sigue siendo muy bajo, el comercio crece y al parecer seguirá a ritmo acelerado. $\mathrm{Si}$ bien el regionalismo avanza en estas dos partes del mundo, hasta ahora no ha afectado los vínculos entre los dos grupos de economías aquí analizados; de hecho, últimamente el comercio interregional ha crecido más que el intrarregional en la mayora de ellas. Al parecer, las relaciones económicas de corto plazo entre estas economías latinoamericanas y asiáticas dependerán en gran medida de que una "segunda generacion" de reformas en América Latina preserve las ventajas conseguidas con las reformas anteriores. Estos cambios exigirán un Estado rehabilitado, en momentos en que ya se ha gastado gran parte de su capital político y subsiste, sin embargo, la necesidad de mantener la integridad fiscal. Parte de la solución para las economías latinoamericanas parece residir en la ampliación y profundización de los acuerdos formales de integracion y sobre todo del Tratado de Libre Comercio de Norteamérica, que puede contribuir a una mayor integración con las economias dinámicas de Asia. Por último, aunque el foro Cooperación Económica en Asia y el Pacífico (APEC) es un puente institucional obvio entre ambas regiones, quizás sea prematuro especular demasiado sobre su importancia potencial. Al parecer se alzan algunos obstáculos formidables en la senda hacia un área de libre comercio en la Cuenca del Pacífico. 
I

\section{Introducción}

Es indudable que las modalidades de inversión y comercio mundiales se vienen configurando en parte debido a una proliferación de acuerdos regionales de integración. En América Latina y el Caribe, por ejemplo, donde tales acuerdos se han multiplicado últimamente hasta bordear la treintena, las exportaciones intrarregionales expresadas como parte de las exportaciones al resto del mundo han aumentado espectacularmente de $13 \%$ en 1990 a un $22 \%$ estimado en 1994 (CEPAL, 1994). Es más, las decisiones trascendentales de avanzar en pos de áreas de libre comercio regionales, tomadas en la Cumbre de las Américas de diciembre de 1994 y en la Cumbre del APEC en noviembre de 1994, podrían influir notoriamente en las modalidades futuras de comercio e inversión.

¿Cómo afectará a las relaciones económicas Sur-Sur el desarrollo de tales tendencias? El presente estudio es un modesto esfuerzo por evaluar parte del cuadro examinando las relaciones economicas entre las economías latinoamericanas (ELA) y las econo- mías dinámicas del Asia en desarrollo (EDA), centrándose en tres economías latinoamericanas, a saber, Brasil, México y Venezuela (que en conjunto generan aproximadamente $65 \%$ del producto interno bruto de América Latina y el Caribe) y sus relaciones con ocho economías asiáticas: China, Hong Kong, Indonesia, Malasia, la República de Corea, Singapur, Tailandia y Taiwán, provincia de China.

En las secciones siguientes se reseñan las tendencias recientes del comercio exterior y la inversión extranjera directa entre ambos conjuntos de economías (sección II); se analizan hasta cierto punto las perspectivas de corto y largo plazo de las relaciones entre las ELA y las EDA, se busca determinar qué cabe extrapolar de los datos, y se yuxtaponen las perspectivas de una mayor integración intercontinental y de una integración continental creciente para verificar hasta qué punto ambas son compatibles (sección III). Por último, se formulan algunas conclusiones (sección IV).

\section{II}

\section{Tendencias del comercio exterior y de la inversión extranjera directa}

Según datos del FMI (1987 y 1993), se observa que aunque el intercambio entre ambos conjuntos de economías sigue siendo muy bajo, su crecimiento en los últimos años ha sido muy alto. El comercio de Brasil, México y Venezuela con las ocho economías asiáticas en 1992 fue de $6 \%, 3 \%$ y $2 \%$, respectivamente, del comercio total de estos países. El comercio de las ocho economías asiáticas con las tres latinoamericanas (en conjunto) osciló entre $0.5 \%$ y $1 \%$ del intercambio de la economía asiática con el mundo. De hecho, el comercio de estas EDA con toda América Latina no es mucho mayor; fluctúa entre $1 \%$ y $3 \%$ para cada una de ellas.

Sin embargo, como se ha dicho, el crecimiento del intercambio ha sido elevado. $\mathrm{El}$ comercio de las
EDA con Brasil y Venezuela entre 1980 y 1992 creció a una tasa media anual de $12 \%$ y con México a una superior a $18 \%$, mientras que en 1989-1992 su comercio con México y Venezuela creció en promedio un $32 \%$ aproximadamente.

La expansion del comercio de México y Venezuela con las EDA se debió a un gran aumento tanto de las exportaciones como de las importaciones. En el caso de Brasil, el grueso del incremento en 19801992 obedecio a las crecientes exportaciones brasileñas a los mercados asiáticos, aunque últimamente el aumento de las importaciones de Brasil desde Asia ha superado al de sus exportaciones a las EDA. Salvo las importaciones brasileñas, la mayoría del comercio entre las tres ELA y las ocho EDA corresponde a 
bienes manufacturados (Naciones Unidas, 1992a, 1992 b y 1993).

Estas tasas de crecimiento del comercio interregional son impresionantes bajo cualquier concepto: por ejemplo, si se las compara con el crecimiento del comercio mundial en los años ochenta y comienzos de los noventa, que borde 6 una tasa media anual de $6 \%$, con el crecimiento del comercio de las 11 economías consideradas con el mundo, y con el crecimiento del comercio intrarregional.

Según datos que provienen principalmente del Centro de las Naciones Unidas sobre las Empresas Transnacionales (CET, 1992), la Organización de Cooperación y Desarrollo Económicos (OCDE, 1993) y la CEPAL (1993), y reconociendo las numerosas limitaciones y vactos en la información disponible, se observa que los flujos interregionales de inversión extranjera directa (IED) entre los dos grupos de economías considerados son probablemente mucho menores que los flujos comerciales correspondientes. Aunque América Latina y Asia han venido recibiendo últimamente corrientes sustanciales de IED, la mayor parte de esta inversion ha provenido de las economías de mercado industrializadas. De hecho, los flujos de IED entre las ELA y las EDA expresados como proporción de la IED entrante, han tendido a ser insignificantes (menos de 1\%). Las excepciones serían Taiwán, provincia de China, donde el 3.1\% de la IED entrante entre 1986 y 1990 provino de América Latina, y México, donde el $8.5 \%$ de la IED entrante en 1992 provino de todos los países en desarrollo, lo que significa que probablemente provino en gran medida de las EDA.

Las cifras de IED aparecen mayores en algunos casos, aunque siguen siendo exiguas, si se miden los flujos como proporción de la IED saliente. Desde fines de los años ochenta hasta comienzos de los noventa aproximadamente $10 \%$ de la IED de la Re- pública de Corea y de Taiwán, provincia de China, se destinó a América Latina. De la IED de China alrededor de $4 \%$ fue a esta última región en 1987 . El grueso de la inversión directa de las EDA en América Latina parece ser en bienes manufacturados con uso intensivo de mano de obra (como textiles y vestuario) destinados al mercado estadounidense. En cuanto a Brasil, la salida de IED hacia las EDA en 1992 fue inferior a $0.5 \%$.

¿Está creciendo la IED interregional? Las pruebas son contradictorias. En general, ha habido un gran incremento de la afluencia de inversiones a las EDA y las ELA, particularmente Venezuela, Indonesia, Malasia, China y México. (La gran excepción es Brasil, donde disminuyó un $13 \%$ la afluencia de IED entre 1989 y 1992.) Sin embargo, cabe recordar que la mayoría de esa inversión proviene de las economías de mercado industrializadas. Además, la salida de inversiones de las EDA crece con rapidez, aunque el grueso de ellas se dirige a las economías de mercado industrializadas o a las propias EDA.

La lectura lógica de los datos disponibles sobre las tendencias de los flujos de inversión entre las EDA y las ELA parecería ser la siguiente. La salida de inversión destinada a las ELA desde China, la República de Corea y Taiwán, provincia de China, se ha venido incrementando en términos absolutos, y al menos en el último caso, también en términos relativos (es decir, la proporción de IED saliente desde la economía taiwanesa hacia América Latina se ha venido incrementando). La salida de IED de las EDA en su conjunto hacia Brasil y Venezuela parece estar declinando. Es probable que la destinada a México esté aumentando. Por último, la salida de IED desde América Latina hacia Taiwán, provincia de China, Malasia y la República de Corea ha aumentado y hacia China, Indonesia, Hong Kong y Tailandia ha disminuido.

\section{III}

\section{Potencial de integración interregional}

El hecho de extrapolar a partir de las tendencias económicas existentes suele ser un ejercicio insustancial, y tal vez más que de costumbre en este caso por varias razones. En primer lugar, América Latina y el Caribe atraviesa una etapa de transición tras la "década perdida" de los años ochenta, y con el serio revés que sufre México actualmente y sus efectos secundarios en otras partes, la transición entra a una etapa nueva e incierta. En segundo lugar, la preferencia por la integración regional como forma principal de integración económica a nivel mundial tal vez esté sólo comenzando. $Y$ por último, hay un reconocimiento 
de que las elevadas cifras de crecimiento del comercio interregional están vinculadas en un sentido a los bajos niveles de intercambio: el incremento dado de un nivel de comercio a otro se traduce en una mayor variación porcentual mientras menor es el nivel inicial. En otras palabras, la tasa de crecimiento del comercio entre ambas regiones podría ser volátil o insostenible.

A continuación, se hará un análisis más detenido de algunas de las variables importantes susceptibles de influir en las relaciones comerciales y de inversión entre las ELA y las EDA. Se comenzará con una evaluación parcial del potencial de comercio entre ambas regiones y de la compatibilidad de las estructuras comerciales. Luego se examinarán las pruebas que avalan el regionalismo a partir de los datos que brinda este estudio. ¿Hasta qué punto ha venido ocurriendo simultáneamente la integración regional e interregional en estas dos áreas del mundo? Y por último, lo que es sin duda más importante, se examinará el papel de las políticas e instituciones en la configuración de los acontecimientos. Esto comprende las políticas del Estado-nación y sus instituciones, y la política intergubernamental y las instituciones supranacionales.

\section{Potencial de comercio entre las economías latinoamerlcanas y las economías dinámicas del Asla en desarrollo}

En esta sección se procura medir en cierto sentido el potencial de comercio equiparando las estructuras comerciales de los interlocutores comerciales. ¿Hasta qué punto, por ejemplo, exporta México (al mundo) lo que importan las EDA (del mundo)? Por cierto, si un país no vende lo que otro país compra habría escaso potencial, a corto o a mediano plazo, para que se expandiera el comercio entre ambos. Por otra parte, si la estructura exportadora del país A se corresponde estrechamente con la estructura importadora del país B, cabría esperar que si ambos países todavía no son grandes interlocutores comerciales, habría un potencial para que lo fueran.

No obstante, conviene destacar algunas limitaciones de este ejercicio. Primero, es indudable que hay otras variables importantes que también determinan las modalidades comerciales presentes y futuras: el crecimiento y el tamaño del mercado, la geografía, la cultura, la historia, las políticas y las modalidades de la IED figuran entre las consideraciones más destacadas.

En segundo lugar, las estructuras comerciales no son inmutables. Por el contrario, una de las características más notables que suelen observarse en las EDA y tal vez ahora último en algunas economías latinoamericanas (como México), ha sido el elemento dinámico que se observa en sus ventajas comparativas; la capacidad de algunas economías de mejorar esas ventajas comparativas ha sido impresionante. Por lo tanto, una "buena correspondencia" sería, en el mejor de los casos, una condición necesaria pero no suficiente para expandir el comercio y, en forma más general, para realzar la integración entre dos áreas a corto y mediano plazo.

Por último, las estructuras comerciales se examinan aquí a un nivel de agregación bastante elevado. En particular en la composición del comercio de las economías en cuestion se distinguieron cinco categorías principales de productos: i) los artículos alimentarios; ii) materias primas agrícolas; iii) combustibles; iv) minerales y metales, y v) manufacturas. A su vez, las manufacturas se desagregaron en tres categorías: i) productos químicos; ii) maquinaria y equipo, y ii) una categoría residual de todas las manufacturas. 1

Este nivel de agregación da una idea de la correspondencia entre las estructuras exportadora e importadora, aunque una mayor desagregación (conforme a la clasificación de tres dígitos de la CuCi por productos o grupos de productos) ofrecería un análisis más significativo de la medida en que un país vende lo que otro compra.

Sobre la base de datos de UNCTAD (1993), la estructura de las exportaciones al mundo de cada una de las tres ELA se cotejó con la estructura de las importaciones desde el mundo efectuadas por las EDA, así como con las estructuras importadoras de los interlocutores comerciales principales y regionales de esas ELA a fin de poder compararlas. También se cotejaron las importaciones de las ELA y las exportaciones de las economias pertinentes.

Las estructuras de exportación-importación se cotejaron de la siguiente manera. La proporción de exportaciones del país A para cada categoría de producto se comparó con la proporción de las importaciones del país B de la misma categoría de producto. Para cada categoría, se determino la proporción menor de ambos países y luego éstas se sumaron a las proporciones menores derivadas de las categorías restantes. Si las estructuras de exportación-importación

\footnotetext{
1 Este esquema clasificatorio concuerda con el utilizado en UNCTAD, 1993.
} 
son idénticas, los componentes sumarán 100 (es decir, una correspondencia perfecta). Mientras más disímiles o incompatibles sean las estructuras, menor será la cifra. La cifra mínima posible es cero. ${ }^{2}$

Sobre la base de las estructuras comerciales (y suponiendo que se eliminan todas las demás influencias), se pueden extraer las siguientes conclusiones. Primero, las oportunidades de exportar a las EDA pa- recerian ser mucho mayores para México y Brasil que para Venezuela (cuadros 1, 2 y 3 ). Lo notable de las mediciones de compatibilidad comercial de las exportaciones de Venezuela a las EDA y otros interlocutores comerciales es la proporción en que las estructuras comerciales parecen incompatibles; en relación con las de Brasil y México las correspondencias suelen ser más débiles. ${ }^{3}$

CUADRO 1

Brasil: Indlce de compatiblidad comerclal (CC), 1990 - 1992

\begin{tabular}{|c|c|c|c|}
\hline & \multicolumn{3}{|c|}{ Proporcion en que Brasil exporta lo que sus interlocutores comerciales importan } \\
\hline & Indice $\mathrm{CC}^{\mathrm{s}}$ & & Indice $\mathrm{CC}$ \\
\hline $\mathrm{BDA}^{\mathrm{b}}$ & 62 & Fstados Unidos & 64 \\
\hline Tigres asiáticos & 63 & Canadá & 60 \\
\hline ASEAN $^{d}$ & 60 & México & 73 \\
\hline China & 64 & Argentina & 56 \\
\hline Singapur & 59 & Italia & 69 \\
\hline Republica de Corea & 61 & Páses Bajos & 74 \\
\hline Hong Kong & 68 & Japón & 73 \\
\hline Taiwán, provincia de China & 62 & Alemania & 73 \\
\hline Malasia & 59 & Prancia & 72 \\
\hline Tailandia & 64 & España & 68 \\
\hline \multirow[t]{3}{*}{ Indonesia } & 57 & Reino Unido & 73 \\
\hline & \multicolumn{3}{|c|}{ Proporcion en que Brasil importa lo que sus interlocutores comerciales exportan } \\
\hline & Indice CC & & Indice CC \\
\hline EDA & 59 & Estados Unidos & 71 \\
\hline Tigres asiáticos & 56 & Canada & 74 \\
\hline ASEAN & 62 & México & 89 \\
\hline China & 61 & Argentina & 48 \\
\hline Singapur & 74 & Italia & 59 \\
\hline República de Corea & 53 & Paises Bajos & 76 \\
\hline Hong Kong & 44 & Japón & 49 \\
\hline Taiwán, provincia de China & 53 & Alemania & 64 \\
\hline Malasia & 73 & Francia & 73 \\
\hline Tailandia & 54 & España & 69 \\
\hline Indonesia & 60 & Reino Unido & 72 \\
\hline
\end{tabular}

Fuente: UNCTAD (1993)

a El indice de compatibilidad comercial varia de 0 a 100; mientras mayor sea la cifra mejor será el "ajuste" y, por ende, mayor el potencial comercial. Para la definición, véase el texto.

b Economías dinámicás del Asia en desarrollo.

- Incluyen Hong Kong, la República de Corea, Singapur y Taiwán, provincia de China.

d Asociación de Naciones del Asia Sudoriental (ASEAN); incluye Indonesia, Malasia y Tailandia.

\footnotetext{
2 Esta medida de la compatibilidad de la estructura comercial emana de Finger y Kreinin (1979), aunque estos autores se centran en la medida en que se equiparan las estructuras exportadoras entre dos socios comerciales. Erzan y Yeats (1991, p. 14) aplican en forma similar el Indice Kreinin-Finger al caso de las estructuras exportadoras en las economías latinoamericanas para medir la magnitud en que las ganancias potenciales provenientes de un área de libre comercio podrían compartirse entre los países con estructuras exportadoras similares.
}

\begin{abstract}
3 En 1991, los combustibles representaban $86 \%$ de las exportaciones de Venezuela. La proporción en que las estructuras importadoras de los interlocutores comerciales son compatibles con la estructura exportadora concentrada de Venezuela depende sobre todo de cuánto petróleo necesitan estos países. Por ejemplo, las cifras indican una compatibilidad relativamente elevada entre las exportaciones venezolanas y la estructura importadora de Brasil y Japón, ambos importadores de combustible. En cambio, se observa una compatibilidad menor en el caso de productores de combustible como China, Malasia y México.
\end{abstract}




\begin{tabular}{|c|c|c|c|}
\hline \multicolumn{4}{|c|}{ Proporcion en que Mexico exporta lo que sus interlocutores comerciales importan } \\
\hline & Indice CC" & & Indice CC \\
\hline \multirow[t]{3}{*}{$\begin{array}{l}\text { EDA' } \\
\text { Tigres asiálicose } \\
\text { ASEANd } \\
\text { China } \\
\text { Singapur } \\
\text { Republica de Corea } \\
\text { Hong Kong } \\
\text { Taiwán, provincia de China } \\
\text { Malasia } \\
\text { Tailandia } \\
\text { Indonesia }\end{array}$} & $\begin{array}{l}71 \\
72 \\
71 \\
67 \\
75 \\
80 \\
60 \\
74 \\
68 \\
72 \\
73\end{array}$ & $\begin{array}{l}\text { Estados Unjos } \\
\text { Canadia } \\
\text { Brasil } \\
\text { Venezuela } \\
\text { Colombin } \\
\text { Argentina } \\
\text { Japon } \\
\text { Alemania } \\
\text { Francia } \\
\text { Espafia } \\
\text { Reino Unido }\end{array}$ & $\begin{array}{l}72 \\
67 \\
89 \\
73 \\
71 \\
70 \\
78 \\
76 \\
78 \\
80 \\
75\end{array}$ \\
\hline & \multicolumn{3}{|c|}{ Proporcion en que Mexico importa lo que sus interiocutores comerciales exportan } \\
\hline & Indice CC & & Indice CC \\
\hline $\begin{array}{l}\text { EDA } \\
\text { Tigres asiaticos } \\
\text { ASEAN } \\
\text { China } \\
\text { Singapur } \\
\text { Republica de Corea } \\
\text { Hong Kong } \\
\text { Taiwan, provincia de China } \\
\text { Malasia } \\
\text { Tailandia } \\
\text { Indonesia }\end{array}$ & $\begin{array}{l}68 \\
71 \\
64 \\
67 \\
85 \\
73 \\
53 \\
73 \\
80 \\
64 \\
48\end{array}$ & $\begin{array}{l}\text { Estados Unidos } \\
\text { Canada } \\
\text { Brasil } \\
\text { Venezuela } \\
\text { Colornbia } \\
\text { Argentina } \\
\text { Japon } \\
\text { Alemania } \\
\text { Francia } \\
\text { Espafio } \\
\text { Reino Unido }\end{array}$ & $\begin{array}{l}94 \\
78 \\
66 \\
14 \\
49 \\
49 \\
78 \\
90 \\
88 \\
91 \\
87\end{array}$ \\
\hline
\end{tabular}

CUADRO 3

Venezuela: Indles de compatibilldad comercial (CC), 1980 - 1992

\begin{tabular}{|c|c|c|c|}
\hline \multicolumn{4}{|c|}{ Proporcion en que Venezuela exporta lo que sus interlocutores comerciales inportan } \\
\hline & Indice $C^{\circ}$ & & Indice CC \\
\hline \multirow[t]{3}{*}{$\begin{array}{l}\text { EDA b/ } \\
\text { Tigges asiáticos of } \\
\text { AsEAN d/ } \\
\text { China } \\
\text { Singapur } \\
\text { Republica de Corea } \\
\text { Hong Kong } \\
\text { Taiwán, provincia de Chira } \\
\text { Malasia } \\
\text { Tajlandia } \\
\text { Indonessia }\end{array}$} & $\begin{array}{l}21 \\
23 \\
20 \\
15 \\
25 \\
30 \\
13 \\
24 \\
17 \\
21 \\
22\end{array}$ & $\begin{array}{l}\text { Estados Unidos } \\
\text { Canadá } \\
\text { Mérico } \\
\text { Colombia } \\
\text { Brasil } \\
\text { Italia } \\
\text { Paises Bejos } \\
\text { Japón } \\
\text { Alemania } \\
\text { Francis } \\
\text { Reino Unido }\end{array}$ & $\begin{array}{l}23 \\
16 \\
16 \\
19 \\
37 \\
23 \\
21 \\
38 \\
21 \\
22 \\
19\end{array}$ \\
\hline & \multicolumn{3}{|c|}{ Proporcion en que Venezuela importa lo que sus interlocutores comerciales exporton } \\
\hline & Indice CC & & Indice $\mathrm{CC}$ \\
\hline $\begin{array}{l}\text { EDA } \\
\text { Tijgres asiáticos } \\
\text { AsEaN } \\
\text { China } \\
\text { Singapur } \\
\text { República de Corea } \\
\text { Hong Kong } \\
\text { Taiwan, provincia de China } \\
\text { Malasia } \\
\text { Tailandia } \\
\text { Indonegia }\end{array}$ & $\begin{array}{l}65 \\
67 \\
63 \\
65 \\
76 \\
71 \\
51 \\
71 \\
80 \\
62 \\
48\end{array}$ & $\begin{array}{l}\text { Estados Unidos } \\
\text { Canadí } \\
\text { México } \\
\text { Colombia } \\
\text { Brasil } \\
\text { Italia } \\
\text { Pafses Bajos } \\
\text { Japon } \\
\text { Alemania } \\
\text { Francia } \\
\text { Reino Unido }\end{array}$ & $\begin{array}{l}88 \\
80 \\
65 \\
47 \\
67 \\
76 \\
78 \\
68 \\
83 \\
91 \\
87\end{array}$ \\
\hline
\end{tabular}

Fuente: UNCTAD (1993).

- El fndice de compatibilidad comercial varí de 0 a 100; mientras mayor sea la cifra mejor será el "ajuste" y, por ende, mayor el potencial comercial, Para la definición, vease el texto.

b Economías dinamicas del Asia en desartollo.

c Inchyen Hong Kong, la República de Cores, Sinzapur y Taiwán, provincia de China.

d Asociación de Naciones del Asis Sudoriental (ASBAN); inchuye lndonesia, Malasia y Tailandia. 
Segundo, tanto México como Brasil tienen un potencial importante para expandir las exportaciones a los mercados de las EDA, aunque el de México parece ser mayor. Esto obedece en parte a que las medidas de compatibilidad suelen ser mayores para las exportaciones mexicanas que para las exportaciones brasilenfas, aumque Brasil exporta una mayor proporción de sus productos que México a las EDA. Además, en ambos países las correspondencias con sus principales interlocutores comerciales son generalmente mejores que con estas últimas. Sin embargo, la diferencia es generalmente menor en el caso de México. Esto querria decir que México tiene mayores posibilidades que Brasil de ampliar sus exportaciones a las EDA.

Tercero, México y Brasil tendrían mayor potencial para ampliar sus exportaciones a las EDA que estas últimas de expandir sus exportaciones a los primeros. Las estructuras exportadoras de México y Brasil se distinguen por tèner un índice de compatibilidad comercial mayor con las estructuras importadoras de las EDA, que las importaciones de Brasil y México con las exportaciones de las EDA.

Además, salvo un par de excepciones relevantes, ${ }^{4}$ las estructuras importadoras de Brasil y México son en general mucho más compatibles con las estructuras exportadoras de sus principales interlocutores comerciales que con las estructuras exportadoras de las EDA. En otras palabras, parece haber buenas razones para que dichos países -en particular los Estados Unidos y algunos países europeossean las fuentes principales de importaciones de Brasil y México, y para que dichas tendencias pudieran mantenerse. La compatibilidad de la estructura importadora de México con sus principales interlocutores comerciales llama mucho la atención; sobre todo en el caso de los Estados Unidos, y también de países europeos (Alemania, Francia, España y el Reino Unido).

Cuarto, las tres El.A tendrían un potencial un poco mayor para expandir sus exportaciones a los mercados de los Tigres asiáticos que a los de la ASEAN. Entre las EDA, el mercado coreano tiene el mayor potencial para ampliar sus exportaciones a México y Venezuela, en tanto que el menor corresponde a Hong Kong. En cambio, la economía a la cual Brasil

4 Las excepciones son las estructuras exportadoras relativamente incompatibles de Japón y Argentina con la estructura importadora de Brasil. Sin embargo, tanto Japón como Argentina figuran entre los cinco principales exportadores a Brasil. Es indudable que estas excepciones subrayan la importancia de otras variables explicativas ya aludidas. tiene más posibilidades de acrecentar sus exportaciones es Hong Kong, y menos posibilidades, Indonesia.

Quinto, entre las EDA, son Singapur y Malasia las economías con mayor potencial de expandir sus exportaciones a los mercados de las tres ELA. Indonesia tendría el menor potencial de ampliar sus exportaciones a México y Venezuela, y las exportaciones de Hong Kong a las tres ELA tienen relativamente poco margen para aumentar.

Por último, resulta instructivo formular algunas observaciones respecto al potencial para el comercio intrarregional en América Latina, ya que en parte condiciona el potencial para el comercio interregional. En primer lugar, hay pruebas de que habría muchas posibilidades de expandir el comercio entre Brasil y Méxjco (tanto en exportaciones como importaciones) más que las de ampliar su comercio con sus principales interlocutores y con las EDA. Esto sugeriría que ambos países podrian tener resultados considerables si establecieran enlaces más formales mediante un acuerdo comercial. Las exportaciones mexicanas también muestran un potencial considerable de expansión a los mercados de otros países latinoamericanos como Venezuela, Colombia y Argentina, el que puede compararse con el orientado a los mercados de las EDA.

En cambio, la correspondencia entre las exportaciones brasilentas y la estructura importadora argentina es bastante reducida. En relación con todas las demás medidas de compatibilidad comercial para las exportaciones brasileñas, es la peor. Esto puede tener efectos interesantes en la evolución del MERCOSUR, del que Brasil y Argentina son los dos miembros dominantes. Este resultado implicaría al menos que a Brasil le convendría mantener diversos interlocutores comerciales.

Por último, las exportaciones venezolanas se corresponden mal con todos sus interlocutores latinoamericanos, si se comparan con las cifras correspondientes para México y Brasil. Además, si se consideran los interlocutores comerciales de Venezuela en el hemisferio y en otras partes (incluidas las EDA), el potencial de expansión de las exportaciones de este país a México y Colombia figura entre los más reducidos, sin perjuicio de que ese mismo potencial figure entre los mayores cuando se trata de Brasil.

\section{Pruebes de la existencla de reglonalismo y de integración interregional}

Es evidente que el incremento de la actividad económica regional y de la interregional no tienen por qué 
ser mutuamente excluyentes. De hecho, el "regionalismo abierto" puede servir para promover mayores vínculos económicos entre las regiones. Más adelante se abordará este tema. En esta sección se persigue examinar primero el historial existente. ¿Hasta qué punto ha venido dándose el regionalismo en América Latina y Asia? ¿Hay pruebas de coexistencia del regionalismo con una integración interregional creciente? $O$, en otras palabras, iel regionalismo -en la medida en que esté ocurriendo - se ha dado a expensas de las relaciones de las economías latinoamericanas con las economías asiáticas consideradas?

Los flujos de comercio e inversion dan algunos indicios, aunque los datos sobre el comercio ofrecen un panorama más completo y actual (cuadros 4 y 5). Este ejercicio se centra en comparar, en la serie cronológica más reciente (1989-1992) y para cada una de las 10 economías en desarrollo examinadas desde este ángulo, 5 el porcentaje de variación media anual del comercio i) con el mundo; ii) con su región, incluidas tanto las economías industriales de mercado como las economías en desarrollo; y iii) con las economías en desarrollo de la "otra" región. ${ }^{6} \mathrm{Se}$ considera que hay pruebas de regionalismo si el crecimiento del comercio de un país con las economías de su región supera el crecimiento del comercio de dicho país con el mundo.

Los resultados son bastante notables. Primero, hay pruebas de regionalismo en los 10 países. Es decir, el crecimiento del comercio de cada país con las economías de su región entre 1989 y 1992 fue mayor que el crecimiento del comercio de ese pars con el mundo.

Segundo, salvo las tendencias comerciales de China y Singapur, el regionalismo no parece estar creciendo a expensas de la integración interregional entre las ELA y las EDA. Es decir, salvo China y Singapur, el crecimiento del comercio de cada ELA con las EDA y de cada EDA con las ELA ha sido mayor que

\begin{tabular}{|c|c|c|c|c|c|c|}
\hline & \multicolumn{2}{|c|}{ Brasil } & \multicolumn{2}{|c|}{ México } & \multicolumn{2}{|c|}{ Venezuela } \\
\hline & $\begin{array}{l}1980- \\
1992\end{array}$ & $\begin{array}{l}1989- \\
1992\end{array}$ & $\begin{array}{l}1980- \\
1992\end{array}$ & $\begin{array}{l}1989- \\
1992\end{array}$ & $\begin{array}{l}1980- \\
1992\end{array}$ & $\begin{array}{l}1989- \\
1992\end{array}$ \\
\hline $\begin{array}{l}\text { Mundo } \\
\text { Economías industriales }\end{array}$ & 2.3 & 4.3 & 9.3 & 23.2 & -0.7 & 6.4 \\
\hline de mercado & 3.5 & 3.0 & 9.9 & 23.8 & -0.3 & 4.6 \\
\hline Economías en desarrollo & 1.0 & 8.5 & 8.0 & 18.8 & .2 .1 & 13.9 \\
\hline Asia & 9.6 & 6.2 & 18.1 & 33.1 & 10,4 & 31.9 \\
\hline $\mathbf{E D A}^{\mathbf{a}}$ & 12.2 & 5.9 & 18.4 & 32.8 & 11.9 & 31.6 \\
\hline China & 4.0 & -10.1 & 4.4 & -2.5 & & ... \\
\hline Hong Kong & 17.9 & 2.6 & 22.7 & 32.7 & 6.6 & 30.4 \\
\hline Indonesia & 2.1 & 10.6 & 18.3 & 36.7 & $\ldots$ & -8.0 \\
\hline República de Corea & 22.9 & 15.4 & 25.8 & 40.3 & 17.4 & 49.0 \\
\hline Malasia & 22.7 & 14.9 & 20.7 & 41.8 & $\ldots$ & $\ldots$ \\
\hline Singapur & 6.9 & 5.1 & 12.7 & 25.7 & $\ldots$ & 64.6 \\
\hline Tailandia & 20.4 & 15.9 & 28.5 & 44.3 & $\ldots$ & \\
\hline Taiwán, provincia de China & 20.9 & 11.0 & 25.3 & 111.4 & $\ldots$ & -0.2 \\
\hline Hemisferio occidental & 4.0 & 7.2 & 10.3 & 25.0 & -0.6 & 8.9 \\
\hline Estados Unidos & 3.9 & 1.9 & 10.4 & 25.4 & 1.8 & 7.9 \\
\hline Canadá & -2.0 & -8.4 & 15.5 & 37,4 & -10.3 & 0.4 \\
\hline ELLA & 4.9 & 17.0 & 6.8 & 14.4 & .2 .9 & 12.5 \\
\hline
\end{tabular}

Fuente:FMI, 1987 y 1993.

a Economías dinámicas del Asia en desarrollo.

b Economías latinoamericanas.

6 Sólo para los fines de este ejercicio, la región correspondiente a Brasil, México y Venezuela incluye, entonces, a todos los paises del hemisferio occidental. La región de las EDA abarca todas las economías asiáticas en desarrollo, además de Australia, Japón y Nueva Zelandia (paises excluidos expresamente en el presente estudio). 
Economias dinámicas dol Aela en desarrollo (EDA): Dlrecolón del comercio, 1980-1992. (Porcentaje de variacion media anual)

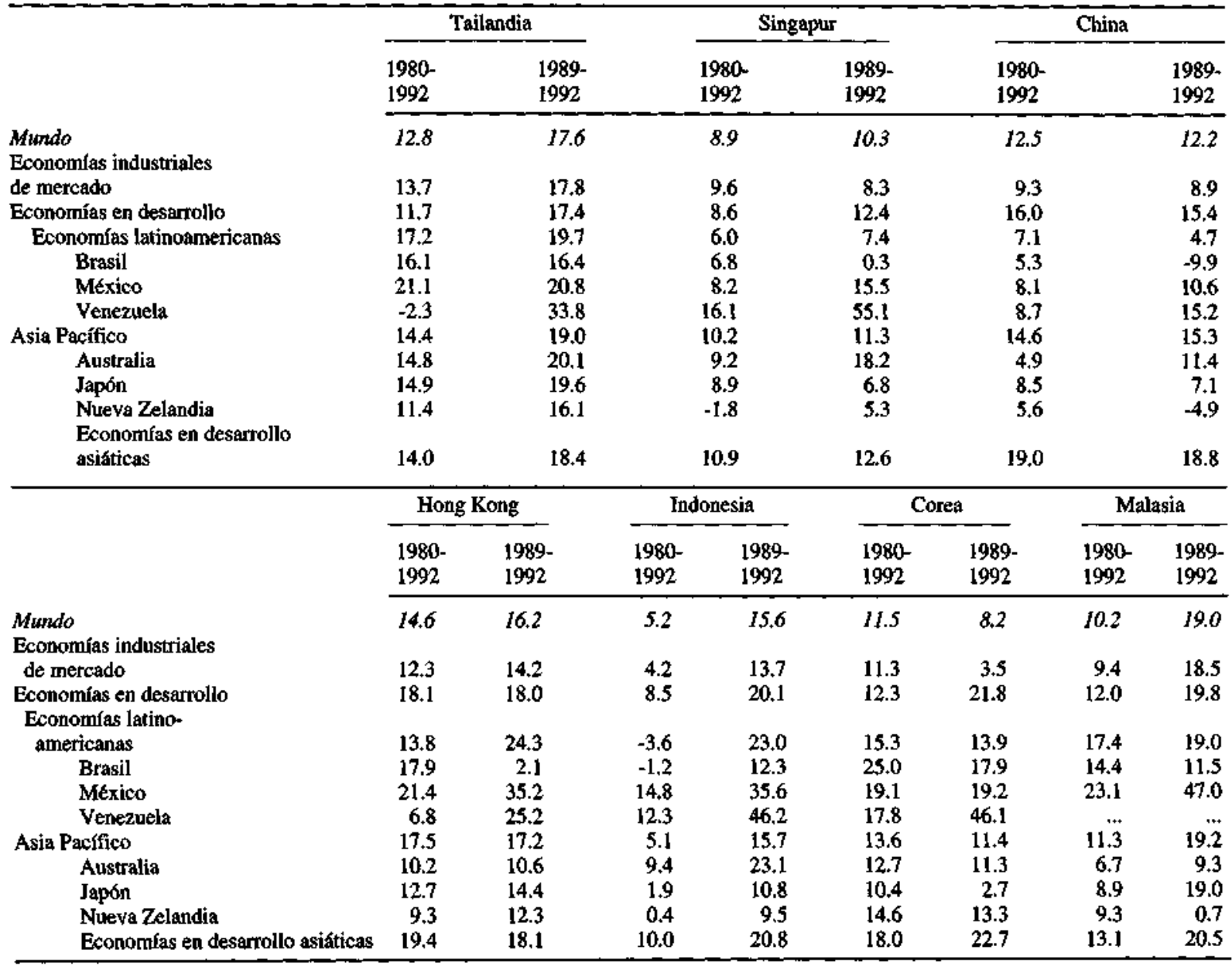

Fuente: FMI, 1987 y 1993.

el de su comercio con el mundo. Esto significa obviamente que el intercambio con algunos otros paises y regiones del mundo está creciendo menos que el de estas ELA y EDA con el mundo. Sin embargo, el comercio entre estas dos regiones del Tercer Mundo no se está resintiendo.

Tercero, en México, Venezuela, Hong Kong, Indonesia, la República de Corea y Tailandia, el crecimiento del comercio interregional supero el crecimiento del comercio regional entre 1989 y 1992 . Los resultados de series cronológicas más largas (1980-1992) que figuran en los cuadros 4 y 5 muestran tendencias similares, aunque menos pronunciadas.

Los resultados sobre el regionalismo y su vinculación con las relaciones entre las ELA y las EDA no son tan definidos en el caso de las tendencias de la
IED (cuadro 6). En parte, el analisis se dificuita por la insuficiencia de datos, ya sea porque no existe información que permita evaluar las tendencias o porque las cifras no son todo lo actualizadas que uno quisiera.

Igual que en el análisis del comercio, se considera que hay pruebas de regionalismo si la entrada (o salida) de IED en un país desde o hacia las economías de su región aumenta con el tiempo como proporción de la entrada (o salida) total de IED.

Respecto de las tendencias de la IED, hay pruebas de que existe regionalismo en las EDA y ninguna prueba de él en las tres ELA No obstante, incluso en las EDA la tendencia no es universal; para Singapur, Hong Kong y la República de Corea la proporción de IED saliente respecto de la IED total que permanece en la region viene declinando. 

Interreglonales do la Inversión extranjera directa, 1980 - 1992

\begin{tabular}{|c|c|c|}
\hline & $\begin{array}{l}\text { Pruebas de } \\
\text { regionalismo }\end{array}$ & $\begin{array}{c}\text { Pruebas de } \\
\text { interregionalismo }\end{array}$ \\
\hline \multicolumn{3}{|l|}{ IED saliente } \\
\hline $\begin{array}{l}\text { Singapur } \\
\text { Hong Kong } \\
\text { República de Corea } \\
\text { Taiwán, provincia de China } \\
\text { Tailandia } \\
\text { Indonesia } \\
\text { Malasia } \\
\text { China } \\
\text { Brasil } \\
\text { México } \\
\text { Venezuela }\end{array}$ & $\begin{array}{l}\text { No } \\
\text { No } \\
\text { No } \\
\text { Si } \\
\text { Si }\end{array}$ & $\begin{array}{l}\text { No } \\
\text { No }\end{array}$ \\
\hline IED entrante & & \\
\hline $\begin{array}{l}\text { Singapur } \\
\text { Hong Kong } \\
\text { República de Corea } \\
\text { Taiwan, provincia de China } \\
\text { Tailandia } \\
\text { Indonesia } \\
\text { Malasia } \\
\text { China } \\
\text { Brasil } \\
\text { México } \\
\text { Venezuela }\end{array}$ & $\begin{array}{l}\text { Sí } \\
\text { Sí } \\
\text { Sí } \\
\text { Sí } \\
\text { Sí } \\
\text { Sí } \\
\text { Sí } \\
\text { No } \\
\text { No }\end{array}$ & $\begin{array}{l}\text { No } \\
\text { Sí } \\
\text { Sí } \\
\text { No } \\
\text { No } \\
\text { Sí } \\
\text { No } \\
\text { No } \\
\\
\text { No }\end{array}$ \\
\hline
\end{tabular}

Fuente: OCDE (1993), CEPAL (1993) y CET (1992).

a Se dice que existen pruebas de regionalismo si la entrada o salida de IFD en una economía desde o hacia las economías de su regíón aumenta con el tiempo como proporción de la entrada (salida) total de IED.

b Se dice que hay interregionalismo si hay un erecimiento proporcional de la IED entre las economías de América Latina y las de Asia.

Las pruebas sobre la coexistencia de regionalismo con un crecimiento (proporcional) de la IED entre las ELA y las EDA son contradictorias, cuando existen, y son pocos los patrones discernibles para explicar el por qué. Algunas economías experimentan ambos fenómenos, otras sólo uno de ellos, y algunas ninguno. Es difícil interpretar cabalmente estas tendencias, ya que los datos son escasos. Esto refleja en gran medida la realidad de que la IED de muchos de estos países en desarrollo sigue siendo relativamente insignificante.

\section{Políticas e instituciones}

Las consideraciones fundamentales de política e institucionales se reducen a dos: las reformas internas en América Latina y el Caribe, y las repercusiones de los acuerdos regionales de cooperación, sobre todo el Tratado de Libre Comercio de Norteamérica (TLCN) y el foro Cooperación Económica en Asia y el PacífiCo (APEC). a) Reformas internas en las economias latinoamericanas

Las reformas radicales realizadas en America Latina han ayudado a alcanzar logros económicos sustanciales. Salvo en Brasil, donde las reformas han tendido a rezagarse, se acelero el crecimiento del producto regional, de $1.5 \%$ anual entre 1985 y 1989 a aproximadamente $3.5 \%$ anual entre 1990 y 1994 (Linde, 1995). La inflación media anual (salvo en Brasil) cayó a $14 \%$ en 1994, un récord histórico en las últimas décadas, si se piensa que en 1989 ascendía a $130 \%$. De continuar estas tendencias, ciertamente se beneficiarán las relaciones economicas entre las economías latinoamericanas y las economías dinámicas del Asia en desarrollo.

La crisis mexicana, sin embargo ha vuelto a subrayar la necesidad de emprender reformas de "segunda generacion". Estas reformas estructurales tienen que considerar al menos dos grandes problemas. Primero, la región en su conjunto sigue encarando grandes presiones desestabilizadoras que se traducen en déficit en cuenta corriente, los que no pueden 
erradicarse sólo con políticas de estabilización. Es crítica la dependencia creciente del capital de cartera extranjero volátil. Esto significa que hay que sostener e incluso acelerar las exportaciones. Respecto del ahorro interno, cabe señalar que las ELA ahorran menos de $20 \%$ del PIB, en tanto que las EDA ahorran el $35 \%$ de él.

Por otra parte, la pobreza generalizada y creciente y la gran disparidad de ingresos de la región, además de ser intolerable, no es sostenible. De hecho, América Latina tiene una de las distribuciones del ingreso más sesgadas del mundo: el $20 \%$ más rico percibe casi 20 veces más ingresos que el $20 \%$ más pobre (Sprout y Weaver, 1992). ${ }^{7}$

Lo paradójico es que a la luz de los esfuerzos bastante exitosos de la región durante los diez últimos años por disminuir el papel del Estado, estos y otros problemas apuntan a la necesidad de reforzar10. ${ }^{8}$ Para que América Latina sostenga y amplíe sus logros, se necesita sobre todo una gobernabilidad eficaz que mejore los servicios públicos en materia de salud y educación, promueva el ahorro, la inversión y las exportaciones, regule mejor los sectores recién privatizados y aliente las reformas tributarias. b) Instituciones intergubernamentales.

Las políticas intergubernamentales, en particular los acuerdos comerciales y de inversión, van a desempeñar también un gran papel en las tendencias interregionales de integración entre las ELA y las EDA. Hasta ahora, el grueso de esta actividad ha sido de caracter intrarregional. En el seno de América Latina han venido floreciendo los acuerdos de integración; en los últumos años se ha desarrollado una trama de unos 30 acuerdos de este tipo que se superponen y a veces son contradictorios. Hasta ahora la integracion asiática ha tendido a ser impulsada más por el mercado que por la política, más informal que formal. Sin embargo, también en este caso los gobiernos están cooperando para aprovechar los logros de mancomunar recursos y ventajas comparativas. 9

$\mathrm{El}$ acuerdo regional que puede tener las mayores repercusiones sobre las relaciones entre las ELA y las EDA en el corto y mediano plazo es el Tratado de Libre Comercio de Norteamérica (TLCN), en gran parte porque uno de sus miembros es Estados Unidos, cuya importancia es vital para todas las economías consideradas. Quizás esto sea más manifiesto en el caso de las ELA. Sin embargo, las EDA también dependen mucho de la economía estadounidense (cuadro 7). La

Asia oriental: importancla del mercado estadounledense, 1993

\begin{tabular}{|c|c|c|c|c|}
\hline & $\begin{array}{l}\text { Exportaciones } \\
\text { totales } \\
\text { (millones de } \\
\text { dólares) }\end{array}$ & $\begin{array}{l}\text { Exportaciones a los } \\
\text { Estados Unidos } \\
\text { (millones de } \\
\text { dolares) }\end{array}$ & $\begin{array}{c}\text { Participación } \\
\text { estadounidense } \\
\text { en las exportaciones } \\
\text { totales (porcentaje) }\end{array}$ & $\begin{array}{l}\text { Lugar que ocupa } \\
\text { Estados Unidos } \\
\text { entre los mercados } \\
\text { de exportación }\end{array}$ \\
\hline $\begin{array}{l}\text { Japón } \\
\text { Tigres asiáticos }\end{array}$ & 362583 & 106898 & 29.5 & 1 \\
\hline $\begin{array}{l}\text { República de Corea } \\
\text { Taiwán, provincia de China } \\
\text { Hong Kong } \\
\text { Singapur }\end{array}$ & $\begin{array}{r}83535 \\
76161 \\
135005 \\
74071\end{array}$ & $\begin{array}{l}18138 \\
22317 \\
31159 \\
15074\end{array}$ & $\begin{array}{l}21.7 \\
29.3 \\
23.1 \\
20.4\end{array}$ & $\begin{array}{l}1 \\
1 \\
2 \\
1\end{array}$ \\
\hline \multicolumn{5}{|l|}{ ASEAN } \\
\hline $\begin{array}{l}\text { Indonesia } \\
\text { Tailandia } \\
\text { Filipinas } \\
\text { Malasia } \\
\text { China }\end{array}$ & $\begin{array}{l}36843 \\
37111 \\
11279 \\
47080 \\
91611\end{array}$ & $\begin{array}{r}5230 \\
8004 \\
4324 \\
9580 \\
16976\end{array}$ & $\begin{array}{l}14.2 \\
21.6 \\
38.3 \\
20.3 \\
18.5\end{array}$ & $\begin{array}{l}2 \\
1 \\
1 \\
2 \\
2\end{array}$ \\
\hline
\end{tabular}

Fuente: FMI (1994).

- Estas cifras corresponden a 1991 y provienen de Ow-Taylor (1993).

7 En cambio, el $20 \%$ más rico de las economáas industriales de mercado percibe siete veces más ingresas que el $20 \%$ más pobre. En Asia oriental, la proporción es incluso más baja, o sea, de seis a uno (Sprout y Weaver, 1992).

8 Véase una exposición bien fundamentada de este concepto en Naim, 1993.
- Cabe recordar el surgimiento de los llamados "triángulos de crecimiento". Hay por lo menos tres: i) el area económica china compuesta por China, Hong Kong y Taiwan, provincia de China; ii) un triángulo de crecimiento entre Indonesia, Malasia y Singapur establecido en 1989, y iii) un acuerdo suscrito en 1993 entre Indonesia, Malasia y Tailandia (véase por ejemplo Vatikiotis, 1993). Además, los países de la ASEAN han venido esforzándose por establecer un área de líbre comercio, aunque los progresos parecen lentos. 
inclusión en este cuadro de Filipinas y Japón destaca aún más la importancia del mercado estadounidense para toda el Asia oriental: en 1993, los Estados Unidos ocupaba el primer lugar entre los mercados de exportación en seis de los diez países asiáticos incluidos en el cuadro, y el segundo lugar en los otros cuatro.

El TLCN también es importante porque inclina considerablemente la balanza global entre regionalismo y multilateralismo. Sumado al viejo sistema de integración europeo que sigue acentuándose y ampliándose, asegura una posición prominente a la integración regional en todo el mundo y podría presionar a los países asiáticos a defenderse, integrándose regionalmente.

Por ende, una de las inquietudes fundamentales es que, con el surgimiento del TLCN, el mundo podría inclinarse por los bloques regionales cerrados. $O$ al menos, el interés en la integración regional podría erosionar el compromiso y el progreso en el foro multilateral del GATT, y ahora en la Organización Mundial del Comercio (OMC). Ninguno de ambos escenarios serviría para promover las relaciones Sur-Sur, ni tampoco la consideración más general del desarrollo del Tercer Mundo (en la mayoría de los casos).

Aún así, aunque el escenario de los bloques cerrados podría concretarse, ello no parece probable en esta coyuntura por dos razones fundamentales. Una es que el proceso multilateral ha sido impulsado por una victoria en la Ronda Uruguay, lo que aumenta la ptobabilidad de que el regionalismo y el multilateralismo se complementen en vez de sustituirse. La otra es que el TLCN no está configurándose como un sistema cerrado. En general éste sería el caso también de los demás acuerdos de integración del hemisferio occidental.

Hay dos criterios importantes para juzgar la apertura del TLCN. Uno se refiere a las barreras al comercio y la inversión de terceros. El otro a las barreras al ingreso a dicho Tratado.

Respecto del primer criterio, el TLCN parecería haber funcionado en general bastante bien. Como se ha sostenido en otra parte, se conforma esencialmente a la "letra" del artículo XXIV del GATT (que sanciona los acuerdos regionales dadas ciertas condiciones), y, lo que es más importante, cuenta con el GATT (hoy OMC) en algunas áreas importantes. En otras palabras, el TLCN posee algunas características positivas del GATT. ${ }^{10}$

Por cierto que el objetivo fundamental del TLCN

\footnotetext{
10 Véase un análisis en este sentido en Hufbauer y Schott (1993).
}

es brindar a los productores que pertenecen al área de libre comercio una ventaja competitiva sobre los demás. Sin embargo, en general, la estrategia parece consistir en no aumentar las barreras respecto del exterior, sino disminuir las barreras internas. Si esto se logra, entonces la creación de comercio sobrepasará a la desviación del mismo, y habrá terceros países que podrán aprovechar también este logro. Los mercados abiertos en expansión ofrecen oportunidades cada vez mayores tanto a los miembros del TLCN como a otros países. Esta es otra manera de destacar la importancia de ponderar los efectos dinámicos (de mayor crecimiento económico) con los efectos estáticos de la desviación del comercio y la inversión.

No obstante, no todo anda sobre ruedas en el TLCN. No cabe duda de que un obstáculo importante son sus normas de origen restrictivas, especialmente en materia de textiles, vestuario y automóviles. Estas medidas parecen destinadas a los competidores del Asia oriental; lamentablemente estas normas podrían en realidad menoscabar la competitividad de muchos productores de la región en el largo plazo. Asimismo, sientan un precedente peligroso para futuros sistemas regionales. Sin embargo, los acuerdos de la Ronda Uruguay sobre estos sectores podrían servir para minimizar la desviación de comercio que causaran las normas de origen restrictivas del TLCN.

Asimismo, sigue habiendo una inquietud legítima respecto al uso del "unilateralismo agresivo" por parte de Estados Unidos en su arsenal de política comercial. De hecho, si Estados Unidos aplicara una política comercial regional desprejuiciada en el TLCN podría incrementar las presiones en pro de medidas antidumping y derechos compensatorios, a medida que los productores estadounidenses afectados por una competencia creciente como resultado del TLCN trataran de resarcirse donde pudieran. Nuevamente, las economías del Asia oriental serían los blancos más probables.

Por último, está la cuestión de adherir al TLCN. Aưnque en teoría esa adhesión está abierta a cualquier país que pueda cumplir con las condiciones económicas establecidas por sus miembros, es evidente que lo que se pretende es transformar al TLCN en el núcleo de un acuerdo de libre comercio hemisférico más amplio. En la Cumbre de Miami, los miembros del TLCN invitaron formalmente a Chile a iniciar negociaciones para ingresar al Tratado, las que están programadas para iniciarse en mayo de 1995. 
Sin embargo, la adhesión al TLCN como miembro de pleno derecho puede que no sea tan importante para los países de fuera del hemisferio. En parte, esto obedece a que hay medios indirectos de adherir a él. Uno de ellos es suscribir un acuerdo de comercio y/o inversión con un país miembro del Tratado. Esto es lo que muchos países han venido haciendo con México. La mayoría de estos acuerdos, aunque no todos, se han suscrito entre México y países del hemisferio occidental. México y Tailandia, por ejemplo, acaban de firmar un acuerdo de expansión del comercio y la inversión. Esto promoverá las inversiones tailandesas en México, y aś Tailandia podrá captar parte del acceso preferencial a los mercados de Canadá y los Estados Unidos. Los esfuerzos de inversión iniciales se traducirán en empresas mixtas (véase Stier, 1992).

El APEC también podría llegar a ser un vehículo formal para que las EDA tengan acceso al mercado norteamericano y, en forma más general, sean un mecanismo para promover los lazos económicos entre las ELA y las EDA. Establecido en 1989 con los modestos objetivos de contar con un foro formal a nivel intergubernamental donde celebrar consultas y analizar la cooperación en asuntos económicos para los países que conforman la cuenca del Pacífico, el APEC sigue ampliándose (sus miembros son ahora 17) y consolidándose, con objetivos más ambiciosos y compromisos crecientes.
Se han formado grupos de trabajo sobre comercio e inversión y en otras áreas. Se ba establecido una secretaría permanente en Singapur. Hasta hace poco, los miembros del Tercer Mundo estaban circunscritos a la vertiente asiática, en particular a las ocho EDA de este estudio, además de Brunei, Darussalam y Filipinas. Sin embargo, México pasó a ser miembro en la reunion de Seattle en diciembre de 1993, y Chile en la de Jakarta en noviembre de 1994.

La principal novedad en la Cumbre de Jakarta fue el acuerdo en principio de establecer un área de libre comercio entre los miembros del APEC para el año 2020. Cómo llegaría a materializarse este acuerdo es una pregunta abierta. Hay por cierto razones para esperar un proceso de negociación mucho más difícil que el del TLCN. La preocupación entre los grupos estadounidenses de que los futuros miembros del área de libre comercio los dejen fuera de competencia será mayor, así como el clamor de sus objeciones. Además, habría mucho menos consenso entre los miembros potenciales sobre los elementos económicos fundamentales. ¿Cuán libre debería ser el libre comercio? ¿Cuánto debería tardarse en concretarlo? ¿Cuál debería ser la secuencia de las políticas? En todo caso, habrá mayores indicios sobre la viabilidad del area de libre comercio en la próxima cumbre que va a celebrarse en el otoño boreal de 1995 en Osaka, Japón, durante la cual se establecerá un plan maestro más concreto. ${ }^{11}$

\section{Observaciones finales}

Al parecer, las relaciones económicas de corto plazo entre las ELA y las EDA dependen sobremanera del proceso de reforma en America Latina y de la evolución del TLCN. Hasta cierto punto, a las ELA les queda la parte más dificil en su dramática puja por competir en la economía mundial. A pesar de lo trascendental de las reformas en cuanto a estabilización y liberalización, se precisan más cambios estructurales delicados para sostener los logros. Estos cambios exigirán un Estado rehabilitado en momentos en que ya se ha gastado gran parte del capital político; pero persiste la necesidad de mantener la integridad fiscal. No obstante, a la luz de los logros extraordinarios alcanzados hasta ahora, habria motivos para tener un optimismo prudente.
Parte de la solución para las ELA residiría en la ampliación y consolidación de los acuerdos formales de integración, y en el TLCN en particular. Además, el crecimiento del regionalismo en el hemisferio occidental parece ser hasta ahora compatible con relaciones interregionales crecientes. De hecho, la importan-

\footnotetext{
"Cabe mencionar dos acuerdos no gubernamentales que fomentan las relaciones entre las ELA y las EDA: la Conferencia de Cocperación Economica en el Pacífico (PECC), establecida en 1980 y cuyos miembros provienen de toxdos los paises del APEC, además de Perú; y el Consejo Económico de la Cuenca del Paćf́ico (PBEC), establecido en 1969 con miembros de nueve países: Japón, la República de Corea, Hong Kong, Australia, Nueva Zelandia, Estados Unidos, Canadá, México y Chile. Para más detalles véase Mattos, 1993.
} 
cia de los lazos económicos entre Asia y las Américas casi asegura este resultado.

No obstante, el TLCN podria afectar la composición de los flujos económicos entre las ELA y las EDA. En particular, dado que habrá algunas consecuencias adversas para las economías del Asia oriental derivadas del TLCN (debido a normas de origen restrictivas y posibles acciones comerciales unilaterales por parte de Estados Unidos), las EDA podrían centrarse más en el corto plazo en la inversión directa en América Latina y menos en el comercio como medio de mantener el acceso al mercado norteamericano.

Por último, aunque el APEC constituye obvia- mente un puente institucional entre las regiones, seria prematuro especular demasiado sobre su importancia potencial. Cabe recordar que hay algunos obstáculos de envergadura que conspiran contra su evolución hacia un área de libre comercio. No obstante, una tendencia que podría contribuir tanto como cualquier otra a una mayor integración entre Asia y las Américas podría darse en Europa. Algunos observadores han sostenido que Europa occidental muestra indicios de privilegiar el bloque cerrado. Al menos, seguirá preocupada por algún tiempo tanto de fortalecerse internamente como de incorporar a sus vecinos del oriente.

(Traducido del inglés)

\section{Bibliografia}

CEPAL (Comisión Económica para América Latina y el Caribe) (1993): Directorio sobre inversion extranjera en América Latina y el Caribe 1993: marco legal e informacion estadistica, LC/R. 1325, Santiago de Chile, Unidad Conjunta CEPAL/UNCTAD sobre Empresas Transnacionales.

(1994): Balance preliminar de la economfa de América Latina y el Caribe 1994, LC/G. 1846, Santiago de Chile.

CET (Centro de las Naciones Unidas sobre las Empresas Transnacionales) (1992): World Investment Directory 1992. Asia and the Pacific, Nueva York, Publicación de la Naciones Unidas, $\mathrm{N}^{\circ}$ de venta E.92.II.A.11.

Erzan, Refik y Alexander Yeats (1991): Prospects for United States-Latin America Free Trade Areas: Empirical Evidence Conceming the View from the South, Washington, D.C., Banco Mundial.

Finger, J. M. y M. E. Kreinin (1979): A measure of export similarity and its possible uses, The Economic Journal, vol. 89, $\mathrm{N}^{\circ}$ 356, Cambridge, Reino Unido, Royal Economic Society.

FMI (Fondo Monetario Internacional (1987, 1993 y 1994): Direction of Trade Statistics, Yeartook, Washington, D.C., FMI.

Hufbauer, Gary Clyde y Jeffrey J. Schott (1993): Western Hemisphere Economic Integration: Implications for the GATT and for Relations with Third Countries, Washington, D.C., Institute for International Economics.

Linde, Armando S. (1995): Latin America and the Caribbean in the $1990 \mathrm{~s}$, Fincance and Development, vol. 32, N 1, Washington, D.C., FMV/Banco Mundial.

Mattos, Jose Carlos (1993): Economic Relations between Latin America and Asia-Pacific: Recent Trends and Future Challenges, Working Paper, $\mathbf{N}^{\circ} 14$, Santiago de Chile, CEPAL, División de Comercio Internacional, Transporte y Financiamiento.
Naciones Unidas (1992a): Commodity Trade Statistics 1987, Brazil, Series D, vol. XXXVII, $\mathbf{N}^{\circ} 1-20$, Nueva York.

(1992b): Commodity Trade Statistics 1990, Venezuela, Series D, vol. XL, $N^{\circ} 1-20$, Nueva York.

(1993): Commodity Trade Statistics 1992, Mexico Series D, vol. XLII, N $N^{\circ} 1-16$, Nueva York.

Naim, Moises (1993): Latin America: Post-adjustment blues, Foreign Policy, $N^{\circ} 92$, Nueva York, Camegie Endowment for International Peace.

OCDE (Organización de Cooperación y Desarrollo Económicos) (1993): Foreign Direct Investment Relations between the $O E C D$ and the Dymamic Asian Economies, Paris.

Ow-Taylor, Chwee Huay (1993): NAFTA: East Asian perspectives, AFTA after NAFTA, Joint Korea-U.S. Academic Symposium, vol. 4, 1994, Princeton, New Jersey, Estados Unidos, Korea Economic Institute of America.

Sprout, Ronald V. A. y James H. Waever (1992): International distribution of income: 1960-1987, Kyklos, vol. 45, Fasc. 2, Basel, Suiza, WWZ and Helbing \& Lichtenhahn Verlag.

Stier, Ken (1992): Thai-Mexico Pact aims to exploit NAFTA advantages, Joumal of Commerce, 4A.

UNCTAD (Conferencia de las Naciones Unidas sobre Comercio y Desartollo) (1993): Handbook of International Trade and Development Statistics 1992, Nueva York, Publicación de las Naciones Unidas, $\mathrm{N}^{\circ}$ de venta E.93.II.D.9.

Vatikiotis, Michael (1993): Three's company: Malaysia, Thailand, Indonesia forge development zone, Far Eastern Economic Review, Hong Kong, Review Publishing Company Limited. 